\title{
As armadilhas do tripé da política macroeconômica brasileira
}

\begin{abstract}
ANDRÉ NASSIF
RESUMO: Este artigo analisa o chamado tripé da política macroeconômica brasileira, que desde 1999 tem combinado um regime de metas de inflação, um regime de taxa de câmbio flutuante e metas de superávit fiscal primário. A menos que o seu modus operandi seja alterado, o tripé não será capaz de libertar a economia brasileira de outra "possível trindade": altas taxas de juros reais, a apreciação da taxa de câmbio real e crescimento econômico muito baixo. Depois de analisar brevemente a base teórica sob o tripé macroeconômico, o artigo mostra por que este regime de política macroeconômica, se avaliado numa perspectiva de longo ou médio prazo, não tem sido capaz de garantir a estabilidade dos preços nem o crescimento econômico. Além da sugestão de romper com a estratégia brasileira de crescer com poupança externa, o documento também sugere três principais formas de mudar o modus operandi do tripé brasileiro: i) aumentar o horizonte de tempo para atingir a meta de inflação, como tem sido o experiência da maioria dos países que adotam esse regime de política monetária; ii) restaurar o papel anticíclico da política fiscal brasileira; e iii) adotar uma combinação de mecanismos que visem prevenir que a moeda brasileira entre em uma nova tendência cíclica da apreciação em termos reais. PALAVRAS-CHAVE: regime de metas de inflação; regime de taxa de câmbio flutuante; superávit primário fiscal; crescimento econômico; estabilidade de preços; Brasil.
\end{abstract}

ABSTRACT: The traps of the tripad of the Brazilian macroeconomic policy. This paper analyses the so-called tripod of the Brazilian macroeconomic policy, which since 1999 has been combining an inflation target regime, a floating exchange rate regime and targets for primary fiscal surplus. I argue that, unless its modus operandi is changed, the tripod will not be able to free the Brazilian economy from another "possible trinity": high real interest rates, real exchange rate appreciation and very low economic growth. After briefly analysing the theoretical base under the macroeconomic tripod, I will show why this macroeconomic policy regime, if it is evaluated in a medium or long-term perspective, has not been able to assure neither price stability nor economic growth. In addition to the suggestion of breaking with the Brazilian strategy of growing with foreign savings, the paper also suggests three

\footnotetext{
* BNDES-Banco Nacional de Desenvolvimento Econômico e Social e UFF-Universidade Federal Fluminense. E-mail: andrenassif27@gmail.com. Submetido: 18/agosto/2014; Aprovado: 12/setembro/2014.
} 
main ways of changing the modus operandi of the Brazilian tripod: i) increase the time horizon for reaching the inflation target, as has been the experience of most countries that adopt this monetary policy regime; ii) restore the countercyclical role of the Brazilian fiscal policy; and iii) adopt a mix of instruments aiming at preventing the Brazilian currency from entering into a new cyclical trend of appreciation in real terms.

KEYWORDS: inflation target regime; floating exchange rates regime; fiscal primary surplus; economic growth; price stability; Brazil.

JEL Classification: E20; E31; E52; E62; F41.

\section{INTRODUÇÃO}

Uma vez tendo iniciado seu segundo mandato para o período 2015-2018 e anunciada sua equipe econômica - com destaque para Joaquim Levy, um economista ortodoxo para o Ministério da Fazenda; Nelson Barbosa, de linhagem "desenvolvimentista" para o Ministério do Planejamento; e a manutenção de Alexandre Tombini na presidência do Banco Central do Brasil - a presidente Dilma Rousseff já avalizou (pelo menos por enquanto) a retomada do chamado tripé da política macroeconômica, adotado no Brasil desde 1999 e caracterizado pelo regime de metas para a inflação, superávits fiscais primários e regime de câmbio flutuante.

O objetivo deste artigo, que segue fielmente os argumentos já apresentados em Nassif e Feijó (2014), pretende responder a uma pergunta simples e direta: a continuidade do tripé, pelo menos replicando os mesmos moldes com base nos quais foi adotado em 1999, será bem-sucedido no sentido não apenas de reduzir a taxa de inflação ao consumidor (IPCA) para o nível da meta preestabelecida pelo Conselho Monetário Nacional (CMN) - de 4,5\% —, mas de retomar o crescimento da economia brasileira sobre bases sustentáveis, situação interrompida praticamente desde o início da década de 1980? Procuraremos argumentar que, a não ser que seja modificado seu modus operandi, o tripé não conseguirá livrar a economia brasileira da armadilha de outra "trindade possível": juros reais elevados, taxa de câmbio real apreciada e baixo crescimento.

Para responder à questão anterior, bem como identificar as principais armadilhas do tripé que, desde 1999, ainda continua amparando a política macroeconômica brasileira, além desta Introdução, o trabalho está dividido em mais três seções. $\mathrm{Na}$ segunda seção analisaremos, de maneira bastante panorâmica, os fundamentos teóricos subjacentes ao modelo do tripé, bem como os principais resultados e problemas a ele inerentes. $\mathrm{Na}$ terceira seção, a título de investigar por que o governo Dilma Rousseff não foi capaz de dar continuidade ao crescimento sustentável da economia brasileira em seu primeiro mandato, uma vez tendo o Brasil conseguido sair relativamente rápido da crise global de 2008 - já em 2010, último ano do segundo mandato de Lula, a taxa de crescimento do PIB real foi de 7,6\% - analisaremos também que tipo de herança negativa (seria uma nova "herança maldita"?) ela terá deixado para o seu segundo mandato. Nesta mesma seção, faremos sugestões de como, a meu ver, deveria ser administrado o referido tripé com vistas a cumprir o triplo objetivo de assegurar o crescimento em perspectiva sustentável, preservar a estabilidade de preços 
e restabelecer o equilíbrio do balanço de pagamentos. Uma vez antecipadas e analisadas as sugestões de política, a última seção, à guisa de Conclusão (quarta seção), tentará responder se a continuidade da política macroeconômica ancorada no atual modus operandi do tripé será capaz de, no médio e longo prazos, assegurar tanto a estabilidade de preços como o crescimento econômico brasileiro.

\section{O TRIPÉ DA POLÍTICA MACROECONÔMICA NO BRASIL (1999-2014)}

Desde 1999, após o severo ataque especulativo de que foi vítima a economia brasileira, a política macroeconômica tem sido guiada pelo chamado tripé regime de metas para a inflação, câmbio flutuante e superávits fiscais primários. Embora não haja um arcabouço teórico articulado para justificá-lo, é lícito sugerir que ele está amparado no chamado consenso macroeconômico que preponderou até a crise global de 2008. Por este consenso, as autoridades governamentais deveriam guiar suas políticas econômicas com base no princípio de que, para cada objetivo a ser almejado, deveria ser implementado apenas um único instrumento de política.

Blanchard et al. $(2010,2013)$ salientam que o referido consenso se ancorava no pressuposto de que o controle da inflação deveria ficar sob o âmago estrito da política monetária que, por meio de um único instrumento (a taxa básica de juros de curto prazo, ou policy rate), se encarregaria de manter estável o nível geral de preços. Ainda de acordo com Blanchard et al. $(2010,2013)$, uma vez que a inflação fosse mantida em níveis baixos e sob controle, a política fiscal teria papel secundário na determinação do produto efetivo real. A defesa de uma política fiscal neutra (ou, nas palavras de Blanchard et al. (2010), de seu "papel secundário") estava ancorada, por sua vez, no princípio da "equivalência ricardiana", segundo o qual qualquer gasto governamental adicional terá efeito nulo sobre o produto real, uma vez que os agentes econômicos, guiados por "expectativas racionais", tendem a incrementar o fluxo de poupança, antecipando, com isso, aumentos esperados de impostos futuros. Ainda que o incremento do gasto adicional do governo tenha sido financiado por expansão da dívida pública, seu efeito será equivalente ao aumento dos impostos, anulando qualquer impacto real sobre a economia.

Trazendo a questão específica da dívida pública para a realidade dos países em desenvolvimento, há relativo consenso em que a mesma deve ser preferencialmente financiada por meio de emissão de títulos e bônus, e não de emissão monetária. A expansão da dívida ao longo do tempo pode ser expressa por meio da equação seguinte:

$$
\dot{D}(t)=[G(t)-T(t)]+r(t) D(t)
$$

em que $D$ é o estoque da dívida no tempo $t$ (o ponto significa taxa de crescimento ao longo do tempo); $G$ os gastos totais do setor público; $T$ os impostos arrecadados; e $r$ a taxa de juros real incidente sobre o estoque da dívida.

A ênfase da visão neoclássica é no crescimento do estoque da dívida pública. Assim, argumenta-se que o problema é que $D$ não pode crescer indefinidamente. Caso o estoque da dívida pública em relação ao PIB ultrapasse determinado nível, 
pode aumentar a desconfiança no mercado quanto à capacidade de solvência da dívida do Tesouro. Admitamos que, uma vez que a dívida pública $D$ atinja esse estoque máximo no tempo $t_{n}$ (ou seja, $D=D_{t n}$ ), aumentem as expectativas de insolvência futura da dívida. Para evitar "dominância fiscal" 1 o governo é forçado a adotar uma política fiscal com superávits primários até que consiga reduzir o estoque da dívida para níveis relativamente baixos e estáveis. A única forma de se combater o crescimento do endividamento público é através da geração de superávits primários que devem ser praticados em níveis tais que, supondo tudo o mais constante, consigam trazer o estoque da dívida pública no tempo $t_{0}$ para um nível relativamente baixo e sustentável.

O problema é determinar qual deveria ser esse nível. Não obstante a famosa controvérsia desencadeada pelo polêmico (e criticado) artigo de Reinhart e Rogoff $(2010)^{2}$, Blanchard et al. (2013) concluíram que um nível de dívida bruta como proporção do PIB em torno de $40 \%$ poderia ser considerado prudente e ampliaria o escopo para que o governo pratique políticas fiscais contracíclicas. No entanto, a equação (1) negligencia importantes aspectos sobre o gerenciamento da dívida pública dos países em desenvolvimento, os quais também interferem nas expectativas dos credores quanto à sua solvência futura. Dentre outros, merecem destaque a maturidade de vencimento dos títulos e os critérios de remuneração dos mesmos (taxas de juros fixa ou flutuante, indexação ou não a moedas estrangeiras, à inflação, etc.). No caso brasileiro, por exemplo, há uma anomalia praticamente inexistente na maior parte dos países, qual seja, o fato de que parte dos títulos públicos emitidos (as Letras Financeiras do Tesouro, as LFTs) é vinculada à taxa básica de juros (a policy rate, no nosso caso, a SELIC). Esse tipo de vinculação sui generis tem um duplo efeito negativo: primeiro, reduz a potência da política monetária quando o Banco Central aumenta a taxa de juros para reduzir a inflação; e, segundo, ao aumentar a taxa de juros, os detentores da dívida contam com um enorme incentivo para aumentar sua posição em carteira na forma desses títulos públicos, uma vez que seu custo de oportunidade e risco é reduzidíssimo, posto que são rolados diariamente no overnight.

\footnotetext{
${ }^{1}$ Ocorre "dominância fiscal" quando o estoque da dívida do governo, ao prosseguir em trajetória ascendente, passa a influenciar as expectativas de inflação e o nível de preços, subordinando a política monetária (leia-se: aumento da taxa de juros) à política fiscal errática. Sob dominância fiscal, o Banco Central passa a aumentar as taxas de juros tanto para combater a inflação como para tornar mais atrativa a venda de montante adicional de títulos públicos. Mas o incremento da taxa de juros, ao aumentar as despesas com juros dos títulos a ela vinculados, acaba por disseminar no mercado maior probabilidade de default. Sob dominância fiscal, a política monetária passa a ser perversa e perde eficácia para deter a inflação. Ver Sargent e Wallace (1981).

${ }^{2}$ Nesse artigo, Reinhart e Rogoff (2010) estimaram uma série histórica para diversos países e concluíram que aqueles com dívida pública/PIB superior a $90 \%$ cresceram menos que os demais. Herndon et. al. (2014), ao replicarem a série histórica daqueles autores, observaram que exclusão de dados relevantes, erros de codificação e ponderação inapropriada de dados estatísticos presentes no estudo de Reinhart e Rogoff (2010) levaram a conclusões equivocadas: no período 1946-2009, os países com dívida/PIB acima de $90 \%$ tiveram uma taxa de crescimento média anual do PIB real significativamente maior $(2,2 \%)$ do que a encontrada na pesquisa de Reinhart e Rogoff (2010), de apenas $-0,1 \%$.
} 
A questão relevante é que, a rigor, desde sua adoção, em 1999, o referido tripé não tem assegurado ao Brasil nem crescimento sustentável, nem estabilidade de preços. Prova disso é que nos 16 anos de existência do regime de metas de inflação (1999-2014), o Brasil só conseguiu alcançar o centro da meta quatro vezes (em 2000, 2006, 2007 e 2009). Na maior parte dos casos, a meta foi cumprida, mas ficou mais próxima do teto máximo de tolerância do que do centro da meta ${ }^{3}$. Além disso, como mostra o Gráfico 1, com exceção da África do Sul, a taxa média anual de crescimento do PIB real no Brasil no período 1999-2011 (3,6\%) foi significativamente inferior à dos demais países que formam o chamado BRICS - exceto África do Sul (Rússia: 5,2\%; Índia: 7,2\%; China: 10,2\%; e África do Sul: 3,5\%) e se igualou à taxa média de crescimento mundial no período.

Gráfico 1: PIB real no Brasil, em países selecionados e no mundo (1999-2011 — em números-índices: $1999=100)$

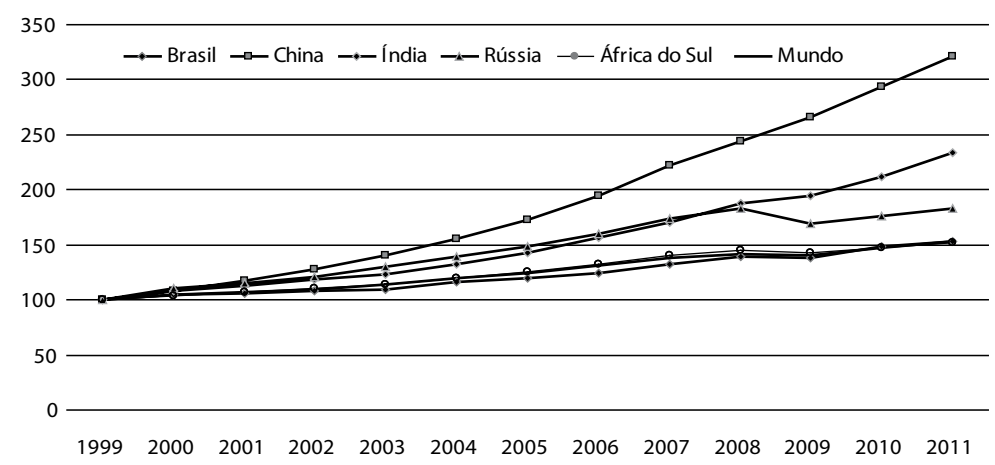

Nota: Dados calculados originalmente em US\$ em paridade do poder de compra (PPP) de 2005. Fonte: Ipeadata, com base em World Development Indicators, do Banco Mundial.

E para tornar as perspectivas menos animadoras, o regime de câmbio flutuante, que, em teoria, deveria servir para amortecer choques e promover o ajuste automático do balanço de pagamentos, tem contribuído - dado o contexto de uma economia extremamente aberta ao fluxo de capitais - para levar a moeda brasileira à uma tendência cíclica de apreciação em termos reais. O Gráfico 2 ilustra tal tendência.

O Gráfico 2 revela dois aspectos nefastos associados ao regime de câmbio flutuante no Brasil. O primeiro é que, como tem sido repetido à exaustão por Bresser-Pereira, o Real brasileiro tem mostrado tendência cíclica de apreciação ${ }^{4}$. Os episódios de depreciação "corretiva" dos desalinhamentos cambiais, quando ocor-

\footnotetext{
${ }^{3}$ Pelas regras do Conselho Monetário Nacional (CMN) — formado pelos ministros do Planejamento, da Fazenda e pelo presidente do Banco Central do Brasil, e que define a meta de inflação anual - a meta é considerada cumprida desde que fique dentro do intervalo de tolerância. No caso brasileiro atual, a meta de inflação é de 4,5\% a.a., com intervalo de tolerância de 2 pontos percentuais para mais e para menos.

${ }^{4}$ Ver, por exemplo, Bresser-Pereira e Silva (2009) e Bresser-Pereira (2010).
} 
Gráfico 2: Taxas de câmbio reais efetivas (junho de $1994=100$ ) e saldos em conta-corrente como proporção do PIB (em percentual) no Brasil: 1999-2013

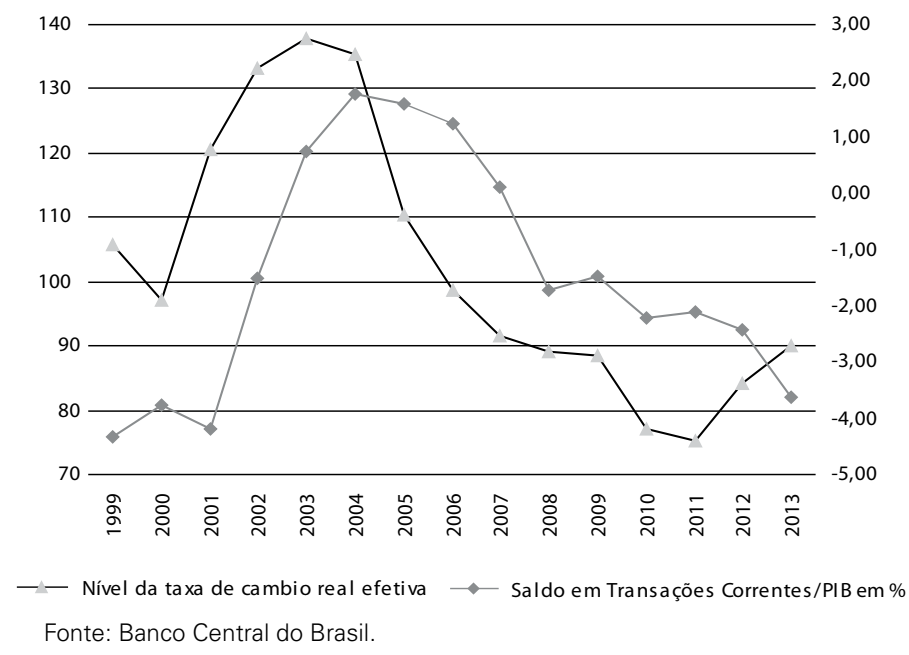

rem, são abruptos e efetivados pelo próprio mercado (a exemplo de 1999, 20022003, 2008 e, novamente, em março de 2015). E, pior, o Banco Central do Brasil, em vez de aprender com os erros do passado e ter aproveitado tais episódios que levaram a taxa de câmbio real para o seu nível "competitivo", adotando algum mix de política cambial mais agressiva (compras de reservas, intervenções nos mercados futuros e mesmo controle ad hoc de capitais) - como passou a fazer grande parte dos países asiáticos após a crise de 1997, como mostraram Aizenman et al. (2010) -, acabou por deixar o Real seguir novas trajetórias de apreciação. Se, por um lado, a apreciação cambial contribui sobremaneira para evitar que a inflação ultrapasse os dois dígitos, por outro lado, ela acaba sendo danosa não apenas para a indústria - afinal o processo de desindustrialização brasileiro é subproduto da sobrevalorização cambial - como para o balanço de pagamentos.

O segundo efeito nefasto está relacionado ao resultado mencionado no final do parágrafo anterior. É marcante a correlação entre as taxas de câmbio reais efetivas e os saldos em conta-corrente. Nos períodos em que a moeda brasileira mostrou maior tendência de depreciação em termos reais (2000-2003), houve redução dos saldos deficitários em conta-corrente observados no período anterior. Depois de alcançar um déficit em conta-corrente de 4,3\% do PIB em 1999, o referido saldo foi reduzido a praticamente zero em 2003. Entre 2004 e 2006, quando a moeda doméstica ainda conseguiu se manter subvalorizada em termos reais, ainda que com tendência à apreciação, o Brasil mostrou superávits em conta-corrente que superavam $1 \%$ do PIB. Essa tendência favorável se reverteu a partir de 2007, quando se passou a observar novo ciclo de apreciação da moeda brasileira em termos reais. No final de 2014, de acordo com dados do Banco Central do Brasil, o déficit em conta-corrente já alcançava significativos US\$ 90,9 bilhões (ou 4,2\% do PIB), uma cifra não sustentável por muito tempo. 
Por outro lado, é fato incontestável que, mesmo tendo apresentado baixas taxas de crescimento do PIB real ao longo da última década, o Brasil tem mostrado considerável progresso nos indicadores sociais. O índice de Gini, depois de evoluir de 0,56 em 1970 para 0,62 em 1977, alcançou o ápice de 0,63 em 19895. Desde meados da década de 1990, graças à estabilização inflacionária, aos programas sociais de transferência de renda e às políticas de valorização do salário mínimo, o grau de concentração de renda, medido pelo índice de Gini, vem sendo sistematicamente reduzido, tendo recuado para 0,53 em 20136. Mesmo reconhecendo que o país precisa melhorar consideravelmente os indicadores relacionados à infraestrutura social e humana (notadamente os relacionados ao saneamento básico, habitação, saúde, educação e mobilidade urbana), tendo em vista que os indicadores de pobreza absoluta ainda são muito elevados para um país de renda média como o Brasil, o fato é que a combinação dos mecanismos de política macroeconômica que vier a ser implementada nos próximos anos deverá, no mínimo, preservar e, preferencialmente, aprimorar os resultados sociais positivamente já alcançados.

\section{O PRIMEIRO MANDATO DE DILMA ROUSSEFF: UMA NOVA "HERANÇA MALDITA"?}

Antes de responder a uma pergunta central deste trabalho - a continuidade do tripé da política macroeconômica dará certo? - , seria conveniente analisar brevemente a herança deixada pelo primeiro mandato da presidente Dilma Rousseff. Uma vez tendo saído relativamente rápido da crise global de 2008 - graças às políticas monetárias e fiscais anticíclicas, as quais, embora implementadas, ambas, com algum atraso, tornaram, pelo menos, a recessão brasileira em 2009 razoavelmente suave (o PIB real teve um declínio de $-0,2 \%)^{7}$ - o Brasil apresentou uma taxa de crescimento surpreendentemente elevada em 2010 (de 7,6\%), último ano do segundo mandato do governo Lula. A questão inicial a perguntar é: por que o crescimento efetivado nesse período (4,6\% entre 2007 e 2010) não se sustentou, já que entre 2011 e 2014 (correspondente ao primeiro mandato de Dilma Rousseff), o PIB real brasileiro apresentou uma taxa de crescimento média anual de apenas $2,1 \%$ ? (Ver Tabela 1, adiante.)

A principal resposta oficial, antes das últimas eleições, era que o Brasil ainda

\footnotetext{
${ }^{5}$ Esses indicadores corroboram evidências empíricas recentes a respeito de diversos países desenvolvidos e em desenvolvimento de que elevadas taxas de crescimento econômico não implicam necessariamente melhora no padrão da distribuição setorial e/ou pessoal da renda nacional. Ver Piketty (2014).

${ }^{6}$ O índice de Gini de 1970 está documentado em Rocha (2004). Os demais seguem as informações das diversas Pesquisas Anuais por Amostras de Domícilio (PNADs), do IBGE (http://www.ibge.gov.br).

${ }^{7}$ Comparado ao governo indiano que, tão logo se defrontou com os primeiros contágios negativos da quebra do banco americano Lehman Brothers (já em setembro de 2008), imediatamente deu início a um ciclo de redução de juros (mesmo com inflação elevada e em aceleração) e aumento de gastos públicos, as políticas anticíclicas no Brasil só foram implementadas com maior vigor no início de 2009. Para maiores detalhes, ver Nassif (2010).
} 
se ressentia da crise mundial, pois, afinal, os países desenvolvidos (notadamente, os Estados Unidos, os países mais ricos da Zona do Euro e o Japão) ainda mostravam baixo crescimento em 2014, passados seis anos após a eclosão da crise global. O problema com esse tipo de argumento é que os países em desenvolvimento e emergentes em geral têm exibido taxas de crescimento médias anuais do PIB real próximas a $5 \%$ a partir de 2012 , e os países em desenvolvimento de baixa renda têm crescido a taxas próximas a $6 \%$ em igual período (ver International Monetary Fund, 2014, p. 2). Ainda que o contexto de incerteza internacional persista, cabe aqui argumentar que os principais entraves à retomada do crescimento econômico brasileiro de forma sustentada estão relacionados predominantemente a fatores de natureza doméstica.

Logo no primeiro ano de governo de Dilma Rousseff, o novo presidente do Banco Central do Brasil, Alexandre Tombini, antecipando-se ao cenário de agravamento nos países da Zona do Euro, iniciou, mediante decisões do COPOM, um ciclo de sucessivas reduções das taxas básicas de juros de curto prazo (SELIC). Entre setembro de 2011 e abril de 2013, a SELIC foi reduzida de $12 \%$ a.a. para 7,25\% a.a., correspondendo a uma queda na taxa de juros real básica de curto prazo (ex-post) de $5,2 \%$ a.a. para $1,3 \%$ a.a. no mesmo período. O problema a investigar é por que tal ciclo de queda dos juros não se sustentou de forma permanente, uma vez que, a partir de meados de abril de 2013, devido à pressão inflacionária e ao aumento das expectativas de inflação, o Banco Central dava início a um novo ciclo de alta dos juros básicos. Embora haja uma diversidade de artigos procurando investigar por que as taxas de juros não se reduzem de forma estrutural e definitivamente para níveis compatíveis com o padrão internacional ${ }^{8}$, podemos especular que, no caso brasileiro, em particular, isso não aconteceu (e, talvez, não aconteça, caso permaneça intocado o modus operandi da política macroeconômica atual) por conta não apenas das contradições da política macroeconômica do primeiro mandato de Dilma Rousseff, mas também devido ao manejo do tripé macroeconômico no Brasil (metas de inflação, superávits fiscais primários e câmbio flutuante).

No que tange ao primeiro motivo, como afirmamos anteriormente, a incerteza global deveria também ter exercido o mesmo efeito adverso na maioria dos países em desenvolvimento, o que não foi o caso. No caso brasileiro, em particular, a incerteza foi agravada pelas próprias contradições da política macroeconômica. De fato, em célebre entrevista concedida ao jornal Valor Econômico de 17 de dezembro de 2012, o secretário de política econômica do Ministério da Fazenda, Márcio Holland, afirmava que "a combinação de juro baixo, câmbio competitivo e consolidação fiscal formam o tripé da nova matriz econômica brasileira". Não pairam dúvidas de que os três objetivos mencionados por um dos principais policy-makers brasileiros são almejados por economistas de distintas filiações teórico-acadêmicas. O problema é que a nova matriz econômica não passou de um emaranhado de contradições.

A principal delas pode ser detectada nos dados da Tabela 1.

${ }^{8}$ Ver Arida, Bacha e Resende (2005) e Bacha (2011). 
Tabela 1: Taxas de crescimento médias anuais do PIB real (1999-2014 - em percentual)

\begin{tabular}{|c|c|c|c|c|c|}
\hline & PIB & $\begin{array}{c}\text { Consumo } \\
\text { das Famílias }\end{array}$ & $\begin{array}{c}\text { Consumo do } \\
\text { Governo }\end{array}$ & $\begin{array}{c}\text { Formação Bruta } \\
\text { de Capital Fixo }\end{array}$ & $\begin{array}{c}\text { Exportações } \\
\text { líquidas * }\end{array}$ \\
\hline $1999-2002$ & 2.1 & 1.7 & 2.2 & -2.1 & 13.2 \\
\hline $2003-2006$ & 3.5 & 3.2 & 2.5 & 4.3 & 0.6 \\
\hline $2007-2010$ & 4.6 & 5.8 & 3.9 & 10.0 & -12.8 \\
\hline $2011-2014$ & 2.1 & 3.1 & 2.2 & 1.8 & -2.5 \\
\hline $1999-2014$ & 3.1 & 3.4 & 2.6 & 3.1 & -0.1 \\
\hline
\end{tabular}

Nota: * Diferença entre taxas de crescimento média de exportações e importações.

Fonte: IBGE, Contas Trimestrais, Série encadeada a preços constantes de 1995.

Ali, é possível constatar que, no primeiro mandato de Dilma Rousseff (2011-2014), o consumo do governo cresceu apenas 2,2\% a.a. a preços constantes de 1995 - de acordo com a série encadeada do IBGE —, configurando taxas de crescimento daquela componente da demanda agregada inferiores aos dois mandatos do governo Lula da Silva e idêntico ao do último mandato de FHC. Portanto, não parece ter havido uma explosão dos gastos do governo (em termos reais) ao longo da gestão de Dilma Rousseff. De todo modo, é preciso reconhecer que, entre 2011 e 2014, os gastos totais a preços correntes do setor público brasileiro tiveram uma taxa de crescimento média anual significativamente superior à do PIB nominal (11,6\% a.a. e 8,7\% a.a., respectivamente), situação que não pode se prolongar indefinidamente, a não ser gerando instabilidade fiscal no longo prazo'. Em que pese este reconhecimento, reiteramos que no final do primeiro mandato de Dilma Rousseff o Brasil não se encontrava na iminência de qualquer crise fiscal de grandes proporções.

A mesma Tabela 1 fornece a pista para encontrar a raiz principal da incerteza e das contradições da política econômica. É possível notar que, ao longo do governo Dilma Rousseff, a taxa de crescimento média da formação bruta de capital fixo no período 2011-2014 foi medíocre, de apenas 1,8\% a.a., inferior tanto à taxa de incremento do consumo do governo como do consumo das famílias e significativamente menor do que a do investimento bruto nos dois mandatos do governo Lula da Silva. Em outras palavras, num cenário de incerteza econômica e baixa propensão dos empresários privados a tomar decisões de investimento, caberia ao governo sinalizar com programas de investimentos públicos (sobretudo em obras de infraestrutura física e humana, bem como em programas para aprimorar a mobilidade urbana, além dos gastos na melhoria de capital humano, isto é, em saúde e educação). Basta verificar que, no período 2011-2013, do total do investimento bruto relativamente ao PIB (média anual de 18,6\%, cifra considerada muito baixa, quando comparada com diversos países em desenvolvimento da Ásia), o governo central participou com mísero 1,3 ponto percentual, segundo dados do Banco

\footnotetext{
${ }^{9}$ Dados calculados pelo autor com base nas estatísticas da Secretaria do Tesouro Nacional/Ministério da Fazenda e nas Contas Nacionais do IBGE.
} 
Central do Brasil. Contrariamente, o Ministério da Fazenda seguiu insistindo na concessão de reduções e/ou isenções tributárias na compra de bens de consumo duráveis. Além de mostrar sinais contraditórios aos empresários - de um lado, o Banco Central retomava o ciclo de aumento das taxas de juros de curto prazo para deter a inflação e as expectativas inflacionárias; de outro lado, o Ministério da Fazenda seguia concedendo incentivos ao consumo das famílias, recurso que, embora justificado nos dois anos imediatamente posteriores à erupção da Grande Recessão Global (em 2009 e 2010), tornou-se contraproducente para induzir as famílias a ampliarem os gastos, dado o quadro de incerteza vigente.

Outra medida inicialmente engenhosa e notável que acabou mais tarde perdendo sua eficácia foi o Programa de Sustentação do Investimento (PSI), linha de crédito com taxas de juros subsidiadas do Banco Nacional de Desenvolvimento Econômico e Social (BNDES), criada no auge da crise de 2009 para substituir a extrema escassez de crédito de curto e de longo prazo ao setor privado. $\mathrm{O}$ programa funcionou bem entre 2009 e meados de 2012, quando eram mais agudos os impactos da crise financeira global sobre a economia brasileira e o grau de confiança empresarial era rapidamente cadente ${ }^{10}$. De acordo com a Sondagem Conjuntural da Confederação Nacional da Indústria (CNI), no período subsequente, entre agosto de 2012 e maio do ano seguinte, houve leve melhora tanto no grau de confiança nas condições presentes, como nas expectativas empresariais futuras. No entanto, a taxa de investimento como proporção do PIB não mostrou forte reação ao longo desse período. Prova disso é que, depois de alcançar o nível de 19,3\% do PIB em 2011, o indicador recuou para $18,2 \%$ e 18,4\% em 2012 e 2013, respectivamente ${ }^{11}$. Com nova piora do grau de confiança dos empresários a partir do segundo semestre de 2013, o PSI, de programa keynesiano notável em sua fase inicial, acabou se transformando em supply-side economics de qualidade duvidosa.

Com relação ao tripé macroeconômico, enquanto regime de política que consiga, simultaneamente, preservar a estabilidade de preços e retomar o crescimento sustentável, o principal problema está, a meu ver, relacionado ao manejo do regime de metas de inflação. Antes de responder à questão principal deste trabalho, convém discutir como deveria ser modificada sua governança, de tal sorte a permitir não somente que as taxas de juros reais se reduzam estruturalmente (e não conjunturalmente) para níveis baixos e estáveis, mas também que a taxa de câmbio real permaneça em torno de seu nível considerado competitivo (segundo estimativas econométricas de Nassif, Feijó e Araújo (2015), algo em torno de R \$2,90/US\$). A convergência destes dois preços macroeconômicos fundamentais é condição sine qua non para que a economia brasileira, ceteris paribus, se reencaminhe para um processo de crescimento sustentável no longo prazo $^{12}$.

\footnotetext{
${ }^{10}$ Ver Sondagem Conjuntural da Confederação Nacional da Indústria (CNI).

${ }^{11}$ Ver IBGE (http://www.ibge.gov.br).

${ }^{12}$ Este trabalho está longe de sugerir que a correção de tamanha sobrevalorização cambial que vigorava ainda nos idos de 2014 fosse feita de uma só vez por meio de uma maxidesvalorização. Como mostraram
} 
A primeira providência seria modificar urgentemente o horizonte temporal para o alcance da meta de inflação. Num estudo do Fundo Monetário Internacional sobre o manejo do regime de metas de inflação em diversos países (ver Heenan et al., 2006, p. 19), nota-se que o Brasil é um dos poucos "bobos da corte", posto que utiliza apenas 1 ano calendário para o alcance do centro da meta, ao passo que a maioria dos países utiliza um intervalo de tempo maior (por exemplo, Canadá: 5 anos; Coréia do Sul: 3 anos; Chile: médio prazo). ${ }^{13}$ Dado o elevado nível de indexação da economia brasileira e a enorme dificuldade para atingir o centro da meta desde a introdução do regime, em 1999, é mais do que conveniente aumentar o horizonte temporal para 2 anos $^{14}$. Com isso, ampliar-se-ia consideravelmente o espaço de política (policy space) para que o Banco Central mire dois objetivos mediante o manejo das taxas de juros (a redução da inflação e o crescimento do produto e do emprego).

A propósito, o debate acadêmico com respeito à arquitetura de novos arranjos para as políticas monetária, fiscal e cambial, em substituição ao antigo consenso macroeconômico prevalecente até a crise global de 2008, está bem mais avançado nos Estados Unidos do que aqui. Apenas para dar uma ideia, no novo livro organizado por Akerlof et al. (2014), o artigo de Janet Yellen (2014, p.p 31-44) sobre novos mecanismos de política monetária tem o sugestivo título de "Many Targets, Many Instruments: Where Do We Stand?”. Neste ensaio, Yellen (2014, p. 31) sugere que os países que adotam regimes de metas de inflação optem pelo do tipo de "metas flexíveis". A sugestão da autora é consistente com o que sugerimos neste artigo. Para Yellen (2014, p. 31), um regime de metas de inflação flexíveis deve possuir as seguintes características: "a commitment to promote low and stable inflation over a longer-term horizon, a predictable monetary policy, and clear and transparent communication” (grifo meu). Além disso, os bancos centrais devem desenhar políticas monetárias

Krugman e Taylor (1978), em artigo "clássico", no curto prazo correções cambiais substantivas reduzem o salário real e, por conseguinte, têm impactos inflacionários e recessivos, devido à queda da demanda agregada (especialmente, consumo). Mas, no longo prazo, taxas de câmbio reais marginalmente depreciadas não somente aumentam o crescimento no longo prazo, como melhoram a distribuição de renda em favor dos trabalhadores. Cabe ressaltar que, em meados de janeiro de 2015, o Real embutia uma sobrevalorização em torno de $12 \%$, mas, em abril de 2011, quando fizemos aquele exercício econométrico pela primeira vez, a taxa de câmbio nominal estava em torno de R \$1,59/US\$, ou seja, embutia uma sobrevalorização de cerca de $82 \%$ ! Ver também Nassif, Feijó e Araújo (2011), em que se pode inspecionar a metodologia sugerida para estimar a "taxa de câmbio real de referência (competitiva) de longo prazo".

${ }^{13}$ Para ser mais exato, neste estudo, Heenan et al.(2006, p. 19) mostram que, num grupo de 24 países que adotam regimes de metas de inflação, somente o Brasil e o Reino Unido operam com um horizonte temporal de 1 ano calendário para o alcance da meta. Todos os demais operam com horizonte temporal maior ou nem sequer definem um prazo para alcançar o centro da meta de inflação.

\footnotetext{
${ }^{14} \mathrm{Na}$ prática, o próprio presidente do Banco Central do Brasil, Alexandre Tombini, em declarações à imprensa, tem ressaltado que o país poderá trazer a inflação para a meta de 4,5\% em 2016, o que significa que a autoridade monetária já incorpora implicitamente tal horizonte. No entanto, o que aqui é sugerido é que esta regra seja modificada e anunciada ao mercado, de forma transparente, pelo Conselho Monetário Nacional (CMN).
} 
com o propósito de "to formulate an inflation goal that would not seem to give preference to price stability over maximum employment" (idem, p. 31).

Com relação ao ajuste fiscal, pode parecer contraditória a sugestão de que o governo recém-empossado agiu na direção correta de sinalizar ao mercado metas de superávits fiscais primários da ordem de 1,2\% para 2015 e 2\% para 2016 e 2017, não obstante o Brasil não se encontre na iminência de uma grave crise fiscal. No entanto, três razões justificam a defesa deste ajuste fiscal: a primeira está ligada ao fato de que a dívida bruta do setor público cresceu significativamente entre o final de 2013 e novembro de 2014 (de 56,7\% para 63\% do PIB); a segunda está ligada ao fato de que a maturity dos títulos públicos brasileiros (ao contrário de países como a Índia, por exemplo, que também possui elevada relação dívida pública/PIB) está ainda concentrada no curto prazo (cerca de $21 \%$ do estoque da dívida pública contabilizada em dezembro de 2014 tinham vencimento em até um ano, de acordo com o Banco Central do Brasil); e terceiro, em virtude das razões anteriores, o referido ajuste é importante não apenas para sinalizar ao mercado compromisso com uma trajetória cadente da dívida, mas também como forma de reduzir a incerteza futura.

No entanto, uma anomalia existente no Brasil é a presença das Letras Financeiras do Tesouro, títulos de altíssima liquidez e negociados no overnight, cuja remuneração é indexada à taxa de juros básica de curto prazo (SELIC). Um dos desafios do Banco Central do Brasil é solucionar esse tipo de imperfeição, em que um título do Tesouro é remunerado pelas taxas de juros básicas de curto prazo (SELIC), cujo objetivo deveria se restringir apenas ao monitoramento dos ciclos do produto real, emprego e inflação. A eliminação dessa anomalia se faz necessária porque, na medida em que uma taxa de policy rate também serve de remuneração para uma modalidade de título público de baixo risco e altíssima liquidez, o reduzido custo de oportunidade relativo à retenção daqueles ativos compete com outras aplicações na esfera produtiva, comprometendo o potencial de crescimento da economia ${ }^{15}$. No longo prazo, a solução ideal é desvincular as remunerações dos demais títulos públicos de taxas pós-fixadas como a SELIC.

Por outro lado, na nova convenção do crescimento não se espera, de forma alguma, que todas as rubricas referentes a receitas e gastos do governo devam ser necessariamente superavitárias. Como regra geral, seja pela necessidade de preservar as enormes conquistas sociais alcançadas nas últimas décadas pela melhoria da distribuição de renda e das condições de bem-estar, seja pela necessidade de continuar garantindo a provisão de bens públicos essenciais, como habitação, saneamento básico, transportes de massa, saúde e educação, dentre outros, não se recomenda que essas rubricas fiquem todas setorialmente superavitárias.

A propósito, o Brasil poderia ser o pioneiro (até onde vai nossa informação,

\footnotetext{
${ }^{15}$ Cabe notar que o Banco Central do Brasil (BCB) parece disposto a eliminar as LFTs como modalidade de títulos emitidos sob responsabilidade do Tesouro, uma vez que sua participação no total de títulos emitidos se reduziu de 40,1\% em dezembro de 2005 para 13,8\% em julho de 2014, segundo as estatísticas do BCB.
} 
não conhecemos qualquer outra experiência que a tenha implementado) numa reforma do orçamento público, em que este tenha suas receitas e despesas separadas, seguindo a recomendação de Keynes (1982), em dois tipos de orçamento: a primeira, relativa ao orçamento corrente, no qual seriam contabilizadas as receitas e despesas correntes do governo (custeio da máquina pública de maneira geral); e a segunda, concernente ao orçamento de capital, no qual seriam contabilizadas as receitas e despesas de investimento em capital físico e humano (infraestrutura, habitação, obras públicas de maneira geral, saúde, educação e segurança). Nesse caso, as metas de superávits primários deveriam se concentrar preferencialmente no orçamento corrente.

Uma vez adotadas as duas propostas concernentes ao manejo da política monetária no bojo do regime de metas de inflação e da política fiscal, a possibilidade de redução definitiva das taxas nominais e reais de juros no Brasil para níveis compatíveis com o padrão internacional aumentaria consideravelmente. Isso significa que na proposição de modificação da governança do tripé — note que não há qualquer sugestão no sentido de eliminá-lo — haveria uma sequência de políticas de ajuste, começando pelas políticas monetária e fiscal. Resta discutir o que poderia ser feito para promover o ajuste cambial. $\mathrm{Na}$ ocasião em que redigia a primeira versão deste artigo (janeiro de 2015), a taxa de câmbio (em torno de R \$2,58/US\$) ainda estava sobrevalorizada e bem abaixo do nível competitivo, o que já não é mais o caso. Ainda assim, na primeira versão do artigo, argumentei que, com a redução das taxas de juros, ficaria igualmente reduzida a atratividade de influxos líquidos muito excessivos de capitais de curtíssimo prazo, cuja natureza é altamente especulativa. Neste caso, teríamos uma primeira força via mercado a atuar na direção de promover pari passu a depreciação do Real. No entanto, também enfatizei que, como nada garantia que as forças de mercado per se seriam capazes de direcionar a taxa de câmbio para o seu nível competitivo real, o Banco Central poderia dar continuidade ao mix de políticas visando ao último objetivo, tais como compras esterilizadas de reservas internacionais, medidas macroprudenciais e, sempre quando necessárias, medidas ad hoc de controle de capitais.

Agora, com a taxa de câmbio em torno de seu nível competitivo real (R \$ 3,08/ US\$, em 10/04/2015, conforme o último registro disponível no website do Banco Central do Brasil), cabe ao Banco Central do Brasil evitar nova tendência cíclica de apreciação. É verdade que no mundo atual da globalização financeira não é tarefa trivial conter a volatilidade cambial, nem tampouco represar a tendência de apreciação, sobretudo nas fases de bonança dos mercados financeiros internacionais. Além disso, para além dos fatores conjunturais, há também forças estruturais que atuam no sentido de apreciar a moeda brasileira de forma cíclica, dentre elas a estratégia implícita (porque não claramente admitida pelos governantes brasileiros) de crescer com poupança externa ${ }^{16}$. Isso significa que, se por um lado, a globalização

\footnotetext{
${ }^{16}$ Para uma crítica da estratégia de crescimento com poupança externa, ver o artigo já “clássico" de Bresser-Pereira e Nakano (2003).
} 
financeira tende a gerar influxos líquidos em demasia de capitais voláteis para os países em desenvolvimento pelo menos até que seus fundamentos macroeconômicos não se tenham deteriorado (em especial, os déficits em conta-corrente), por outro lado uma estratégia de crescimento com poupança externa - da qual o Brasil ainda não se livrou - significa que os policy-makers terão feito previamente a escolha de não reagir ativamente às entradas líquidas maciças de capitais que tendem a apreciar o câmbio. Em suma, para evitar nova tendência cíclica de apreciação, será preciso atuar não apenas pelo lado do mix de políticas anteriormente sugeridas, mas também mudar a própria estratégia brasileira de desenvolvimento econômico.

A grande vantagem das medidas acima propostas é que elas resgatariam a capacidade de a economia brasileira voltar a crescer de forma sustentável, preservando a estabilidade de preços, já a partir de 2016. Com efeito, se por um lado um ajuste fiscal da ordem de $1,2 \%$ do PIB já carrega consigo um caráter fortemente contracionista, as propostas de manter algumas rubricas do orçamento de capital em sentido amplo deficitário (basicamente obras públicas em infraestrutura física e social, mobilidade urbana, educação, saúde e segurança) e de conferir maior espaço para a redução das taxas reais de juros caso fosse modificado o horizonte temporal para o alcance da meta de inflação para 2 anos teriam, por outro lado, um caráter contracíclico expressivo. Desde que anunciadas com transparência, as medidas propostas reduziriam consideravelmente o grau de incerteza ainda vigente e os investimentos públicos exerceriam a força de reativar o animal spirits dos empresários privados, levando à ampliação da taxa de investimento na economia brasileira. Em última instância, poderíamos contar com maior perspectiva de crescimento sem abrir mão da estabilidade.

\section{À GUISA DE CONCLUSÃO: A CONTINUIDADE DO TRIPÉ DA POLÍTICA MACROECONÔMICA DARÁ CERTO?}

As primeiras medidas lançadas pela equipe econômica já sinalizam - caso sejam de fato mantidas da forma como parece que serão adotadas - que o tripé da política macroeconômica está sendo revigorado sobre bases bastante conservadoras. Dentre as medidas já anunciadas e em evolução, cabe destacar pelo menos duas: i) as metas de superávits fiscais primários da ordem de 1,2\% do PIB para 2015 e 2\% do PIB para 2016 e 2017; e ii) a continuidade da política de aumento da taxa de juros básica (SELIC) que, desde maio de 2013, evoluíram de $8 \%$ para 12,75\% em março de 2015. Embora o Conselho de Política Monetária (COPOM) tenha anunciado o último aumento da taxa básica "sem viés", este indicador já conferia ao Brasil, mais uma vez, o status de país com a maior taxa de juros real do mundo (cerca de 5,8\% $)^{17}$. Com tais medidas, aliadas aos demais problemas conjunturais do país - problemas de corrupção na Petrobras, que implicaram a

${ }^{17}$ Jornal O Globo, de 04/03/2015. 
interrupção temporária dos investimentos que haviam sido programados para o setor (com efeitos multiplicadores deletérios em diversos outros setores correlacionados ao setor de petróleo), problemas de oferta de energia elétrica, dentre outros -, estamos diante de uma "tempestade perfeita" rumo à recessão econômica.

Nos últimos meses de 2014 - pouco antes da posse da Presidente Dilma Rousseff para o seu segundo mandato - as incertezas acerca da nova política econômica alimentaram uma forte depreciação do Real em relação ao Dólar americano. Posteriormente, com o agravamento das condições políticas no Brasil, a taxa de câmbio foi abruptamente corrigida para um nível superior ao que havíamos estimado como o "competitivo" (como vimos, de acordo com nossas estimativas, algo em torno de R \$2,90/US\$, embora alguns analistas cheguem a estimar esta taxa para até $\mathrm{R} \$ 3,10 / \mathrm{US} \$)^{18}$.

Nesse período, o Banco Central não fez fortes intervenções no mercado de câmbio, parecendo sinalizar que aprendera definitivamente com os erros do passado e deixaria a taxa flutuar em torno da taxa de câmbio de referência real ${ }^{19}$. Em nossa última consulta ao website do Banco Central do Brasil, a autoridade monetária informava uma taxa de câmbio Real/Dólar de R \$ 3,08 em 10/04/2015, suficiente para, ceteris paribus, promover uma realocação de recursos em direção a setores com maior capacidade para disseminar seus ganhos de produtividade para o restante da economia, assegurando, consequentemente, maior crescimento econômico.

No entanto, é preciso que o Banco Central do Brasil continue "atento e forte" para evitar novas tendências de apreciação, como ocorreram nos diversos períodos subsequentes de realinhamento cambial (após 1999, 2003 e 2008). Diversas episódios recentes podem contribuir para nova tendência de apreciação do Real brasileiro, dentre os quais podem ser mencionados: o primeiro, mais óbvio, diz respeito ao "choque de credibilidade" do mercado financeiro perante as primeiras medidas de ajuste anunciadas pela nova equipe econômica; e ii) o segundo, mais preocupante, pode ser decorrência do anúncio, pelo Banco Central Europeu (BCE), de uma agressiva política de quantitative easing mediante a qual aquela instituição comprará cerca de $€ 60$ billhões mensais (ou $€ 720$ bilhões anuais), a fim de eliminar os riscos de deflação e estimular a rastejante economia da Zona do Euro.

Embora estas últimas medidas possam ter impactos positivos sobre a economia brasileira no curto prazo, elas estão longe de ser benéficas no médio e no longo prazos. No plano internacional, tais medidas poderão contribuir para a migração de recursos dos países superavitários europeus para a compra de títulos públicos e privados nos Estados Unidos, o que poderá contribuir para a valorização do Dólar. A confirmar tal resultado, a política de aumento das taxas de juros no Brasil, ao

\footnotetext{
${ }^{18}$ De acordo com Alberto Ramos, diretor de pesquisas da Goldman Sachs para a América Latina, "hoje (Novembro de 2014) o câmbio de equilíbrio estaria mais próximo de R\$ 3,10". Ver Jornal Valor Econômico, de 24/11/2014.

${ }^{19}$ Para detalhes da estimação econométrica desta taxa, bem como sugestões de como atuar para evitar nova tendência de apreciação, ver Nassif, Feijó e Araújo (2015).
} 
ampliar ainda mais o diferencial entre as taxas de juros internas e internacionais, estimulará, num primeiro momento, influxos expressivos de capitais externos, em especial aqueles sob a modalidade para aplicação em carteira (curto prazo), o que, muito provavelmente, induzirá à maior apreciação da moeda brasileira (em que pese a eventual valorização do Dólar em frente ao Euro). Assim sendo, caso se efetive tal cenário ao longo deste ano, ele muito provavelmente atuará no sentido de reduzir as pressões inflacionárias, bem como de assegurar o financiamento do gigantesco déficit em conta-corrente brasileiro (o qual, como já mencionado, alcançou 4,2\% do PIB em 2014).

É possível que a recessão econômica esperada para 2015 seja "saneadora”, à luz da corrente ortodoxa, no sentido de que, uma vez alcançada a estabilidade inflacionária, a economia ficaria preparada para retomar o crescimento. É possível que algum crescimento possa vir a se tornar efetivo a partir de 2016 ou 2017, mas a questão relevante é: mantido o modus operandi atual do tripé, tal crescimento será sustentável? A resposta mais provável é não, em virtude do fato de que estaríamos replicando um regime de política macroeconômica cujo resultado não tem sido outro senão fazer o cachorro rondar indefinidamente em torno de seu próprio rabo. Num país com ampla abertura ao movimento de capitais, mantido o regime de metas de inflação com a governança rígida como tem sido a brasileira desde 1999, qualquer pressão inflacionária mais adiante (digamos, a partir de 2017) exigiria novo ciclo de alta de juros, o que levaria a novos estímulos a influxos maciços de capitais e maior apreciação do Real. Isso tudo na pressuposição de que, até lá, não ocorra nenhum choque externo significativo, o que poderia pôr em risco a atual sustentabilidade dos elevados déficits em conta-corrente no Brasil. Na hipótese de um choque externo significativo, o Banco Central contaria com duas opções sombrias: i) defender o Real e perder parte significativa das reservas; ou ii) não interferir no mercado de câmbio e deixar o Real depreciar até alcançar um nível de overshooting. Daí por que é possível, mas não será nada fácil encontrar uma saída organizada para promover o reequilíbrio do balanço de pagamentos em conta-corrente brasileiro.

Mantida a atual governança baseada no modelo do tripé, um componente importante na ajuda ao combate à inflação tem sido a tendência estrutural à apreciação da taxa de câmbio real. O elevado patamar da taxa de juros doméstica mantém igualmente elevado o diferencial entre as taxas de juros internas e internacionais, atraindo enormes influxos líquidos de capital externo, em grande parte de cunho especulativo, reduzindo (isto é, apreciando) artificialmente a taxa de câmbio real. Um efeito negativo importante desta tendência é a queda da relação câmbio-salário, que tem comprometido a capacidade competitiva do país nos últimos anos e contribuído para o aprofundamento do processo de desindustrialização no Brasil. A "armadilha" da taxa de juros elevada-câmbio apreciado deveria ser gradualmente desmontada na nova convenção de política econômica. Assim, argumenta-se que se poderia desmontar a "armadilha" na medida em que se abrisse maior espaço para a redução da taxa básica de juros com a nova governança do regime de metas de inflação proposto, bem como com a continuidade da política 
de administração das reservas internacionais e outras medidas macroprudenciais que se fizerem necessárias, para evitar a alta volatilidade na taxa de câmbio. Em relação ao câmbio, o objetivo deve ser o de evitar que ele se desvie novamente da taxa de referência real de longo prazo, de modo que possa trazer benefícios para a competitividade da economia e contribuir para a retomada dos investimentos privados em capital e em inovações. Na medida em que seja possível conciliar retomada do crescimento com melhoria da competitividade, ganhos de produtividade devem compensar a perda de poder aquisitivo dos salários no curto prazo, por força da depreciação cambial. A política salarial na nova convenção, por sua vez, deve preservar ganhos reais. Por outro lado, desde que não haja um choque internacional de proporções dramáticas, é de esperar que a taxa de câmbio atual, já corrigida para seu nível competitivo, venha a se refletir em uma melhora no saldo em conta-corrente, atualmente com déficit significativamente elevado para ser sustentável no médio prazo (4,2\% do PIB em 2014).

Em suma, partindo do diagnóstico de que o atual modelo de política econômica baseado no tripé tem sido contraproducente para assegurar, simultaneamente, crescimento sustentável e estabilidade de preços, além de estar inadequado ao ambiente de elevada incerteza, identificamos a necessidade de uma gradual construção de um novo modelo de política econômica em que metas de crescimento e de estabilidade sejam conjuntamente estabelecidas, e o compromisso com a melhoria na distribuição de renda mantido. A revisão do atual modelo implica resgatar o papel contracíclico da política fiscal, reduzir o papel da taxa de juros como o principal instrumento de política macroeconômica, manter a taxa de câmbio em torno de seu nível competitivo e preservar uma política salarial de ganhos reais pela produtividade. Peça-chave para dar início a esta engrenagem é a recuperação do investimento privado em capital e em inovações tecnológicas, de tal sorte a proporcionar taxas mais expressivas de crescimento da economia, com avanços na produtividade agregada. Tudo isso se tornará possível no instante em que uma nova convenção de política econômica conseguir resgatar o grau de confiança nas expectativas de crescimento da economia brasileira. Infelizmente, as primeiras medidas anunciadas pela nova equipe econômica, no início de 2015, apontam apenas parcialmente para essa direção.

\section{REFERÊNCIAS BIBLIOGRÁFICAS}

AKERLOF, G., BLANCHARD, O., ROMER, D. e STIGLITZ, J. (2014). What Have We Learned? Macroeconomic Policy after the Crisis. Cambridge, MA: The MIT Press.

AIZENMAN, J., Chinn, M.D., e Iтo, H. (2010). "Surfing the Waves of Globalization: Asia and Financial Globalization in the Context of the Trilemma". La Follette Working Papers Series 2010-009. Robert M. La Follette School of Public Affairs. The University of Wisconsin-Madison.

ARIDA, P., BACHA, E. e RESENDE, A.L. (2005). "Credit, Interest, and Jurisdictional Uncertainty: Conjectures on the Case of Brazil”.In: F. Giavazzi, I. Goldfajn e S. Herrera (eds). Inflation Targeting, Deb, and the Brazilian Experience: 1999-2003. Cambridge, Mas.: MIT Press: 265-293.

BACHA, E. (2011). “Além da Tríade: Como Reduzir os Juros?” In: E.L. Bacha e M.B de Bolle (orgs). 
Novos Dilemas da Política Econômica: Ensaios em Homenagem a Dionísio Dias Carneiro. Rio de Janeiro: Gen/LTC: 130-139

BLANCHARD, O., DELL'ARICCIA, G. e MAURO, P. (2010). "Rethinking Macroeconomic Policy". IMF Staff Position Note SPN 10/03. Washington, D.C.: International Monetary Fund.

BLANCHARD, O., DELL'ARICCIA, G. e MAURO, P. (2014). "Rethinking Macroeconomic Policy II". IMF Staff Discussion Note SDN 13/03. Washington, D.C.: International Monetary Fund.

BRESSER-PEREIRA, L.C. (2010). Globalization and Competition. Why Some Emerging Countries Suceeded While Others Fall Behind? Cambridge: Cambridge University Press.

BRESSER-PEREIRA, L.C. e SILVA, C. (2009). "O Regime de Metas de Inflação no Brasil e a Armadilha da Taxa de Juros/Taxa de Câmbio” In: J.L. Oreiro, L.F. de Paula e R. Sobreira (orgs). Política Monetária, Bancos Centrais e Metas de Inflação: Teoria e Experiência Brasileira. Rio de Janeiro: FGV Editora: 21-51.

BRESSER-PEREIRA, L.C. e NAKANO, Y. (2003). “Crescimento Econômico com Poupança Externa?”. Revista de Economia Política. Vol. 23, n 2 (90):3-27.

HERNDON, T., ASH, M. e POLLIN, R (2014). "Does High Public Debt Consistently Stifle Economic Growth? A Critique of Reinhart and Rogoff”. Cambridge Journal of Economics 38: 257-279.

INTERNATIONAL MONETARY FUND (2014). "World Economic Outlook Update: An Uneven Global Recovery Continues". Washington, D.C.: International Monetary Fund, July.

NASSIF, A. (2010). “ Brazil and India in the Global Economic Crisis: Immediate Impacts and Economic Policy Responses” In: S. Dullien, D. Kotte, A. Márquez and J. Priewe (eds.). The Financial and Economic Crisis of 2008-2009 and Devoloping Countries. Geneva: United Nations Conference on Trade and Development (UNCTAD — United Nations):171-201.

NASSIF, A. e FEIJO (2014). "Por uma Nova Convenção de Política Macroeconômcia para o Desenvolvimento com Estabilidade”. Artigo preparado para o $11^{\circ}$ Fórum de Economia da Fundação Getúlio Vargas (FGV-SP), tema "O ajustamento que se faz necessário", realizado em São Paulo, nos dias 15 e 16 de setembro de 2014. mimeo.

NASSIF, A., FEIJO, C. e ARAUJO, E. (2011). "The Long-term "Optimal” Real Exchange Rate and the Currency Overvaluation Trend in Open Emerging Economies: the Case of Brazil”. UNCTAD Discussion Papers $\mathrm{n}^{\circ}$ 206. Geneva: United Nations Conference on Trade and Development (UNCTAD). December (available at http://unctad.org/en/pages/publications/Discussion-Papers-(Series).aspx).

NASSIF, A., FEIJO, C e ARAUJO, E. (2015). Overvaluation Trend of the Brazilian Currency in the 2000s: an Empirical Estimation. Revista de Economia Política, Vol. 35, n 1 (138) (disponível em http://www.rep.org.br).

REINHART, C. e ROGOFF, K. (2010). Growth in a Time of Debt. American Economic Review, Vol.100 (2):573-578

SARGENT, T.J. e Wallace, N. (1981). "Some Unpleasant Monetarist Arithmetic”. Federal Reserve Bank of Minneapolis Quarterly Review, Vol. 5, n 3:1-17;

KRUGMAN, P. e TAYLOR, L. (1978). "Contractionary Effects of Devaluation”. Journal of International Economics 8: 445-456.

HEENAN, G., PETER, M. e SCOTT, R. (2006). “Implementing Inflation Targeting: Institutional Arrangements, Target Design, and Communications. IMF Working Paper WP/06/278. Washington, D.C.: International Monetary Fund.

KEYNES, J.M.(1982). The Collected Writings of John Maynard Keynes In: Moggridge, D e Johnson, E (orgs), Vol.27. Londres: Macmillan para a Royal Economic Society.

ROCHA, S. (2004). "Pobreza no Brasil: O que mudou nos Últimos 30 anos?" Estudos e Pesquisas no 83. Seminário Especial, Miniforum em homenagem aos 40 anos do IPEA. Rio de Janeiro: Instituto Nacional de Altos Estudos (INAE). Setembro.

PIKETTY, T. (2014). Capital in the Twenty-First Century. Cambridge, Mas.: Harvard University Press.

YELLEN, J. (2014). “Many Targets, Many Instruments: Where Do We Stand?” In: G. Akerlof, O. Blanchard, D. Romer e J. Stiglitz. What Have We Learned? Macroeconomic Policy after the Crisis. Cambridge, MA: The MIT Press, 2014. 